\title{
Productive Engagement of Older Adults: International Research, Practice, and Policy Introduction
}

\author{
Nancy Morrow-Howell • Ada C. Mui
}

Published online: 9 October 2012

(C) Springer Science+Business Media New York 2012

By the year 2050, most countries around the globe (with the exception of many in Africa) will have populations where more than $20 \%$ of the people are over the age of 65 years; and there will be more people over the age of 60 than under the age of 15 years. Life expectancy in many developed countries is now approaching 80 years and continues to rise. The developing countries are aging at an extremely rapid rate-these countries are getting old before they are getting rich. The age group of 80 -and-older is the fastest growing group in the world. Fertility rates continue to drop and by 2020, the global fertility rate will dip below the global replacement rate for the first time (Longman 2010). The trends create huge challenges to societies faced with providing economic support and health care to the growing older population, while the younger population is growing more slowly.

The concept of productive aging, or the productive engagement of older adults, has been offered as part of the solution to population aging (MorrowHowell et al. 2001). From this perspective, the successes of population aging are highlighted - the growing capacity of older adults in terms of health and education and the possibility for the first time in human history for people to stay productively engaged in life until their 7th, 8th, even 9th decade. The growing capacity of the older population has not been fully recognized; and it certainly has not been maximally utilized to offset the demands of the changing demographics. Older adults have growing capacity for paid and unpaid work, as employees, volunteers, and caregivers.

\footnotetext{
N. Morrow-Howell ( $\bowtie)$

Harvey A. Friedman Center for Aging and the George Warren Brown School of Social Work, Washington University in St. Louis, One Brookings Drive, St. Louis, MO 63130, USA

e-mail: morrow-howell@wustl.edu

A. C. Mui

Columbia University School of Social Work, 1255 Amsterdam Ave, New York, NY 10027, USA

e-mail: acm5@columbia.edu
} 
Countries across the globe are beginning to rethink outdated policies and programs that view older adults more as "burden" than as "resource."

Countries have a lot to learn from each other. They face similar challenges with population aging, but their populations are aging at different rates, their sociopolitical and economic situations shape the realities for the productive engagement of people of all ages, and unique cultural values affect program and policy responses to the older population. Cross-country research and educational initiatives promise more effective responses to the challenges and opportunities associated with the new realities of the changing demographics.

We began a cross-national dialogue on productive engagement of older adults at a 2009 conference at Shandong University, sponsored by Shandong University, Washington University in St. Louis, the Chinese Academy of Social Sciences, Centre for Social Development Asia at the National University of Singapore, and the Center for Social Development at Washington University. The exchange among conference participants was energetic, and another meeting was planned for 2011. The papers for this special issue were presented at this second conference, Productive Aging in China: Toward Evidence-Based Practice and Policy at Peking University, China, August, 2011. The conference was planned and organized by the Center for Social Development at Washington University in St. Louis, the Hong Kong Polytechnic University-Peking University Social Work Research Centre, Institute of Gerontology at Renmin University of China, and China Association of Social Work Education. We are grateful to our sponsors for generous support to make this conference possible. They are Tin Ka Ping Foundation, ZeShan Foundation, Social Policy Research Center of National Taiwan University, Department of Social Work and Social Administration at the University of Hong Kong, Centre for Social Development Asia at National University of Singapore, Community Foundation for Southeastern Michigan, Committee of Professional Social Workers of China Association of Social Workers, and Chancellor's Office at Washington University in St. Louis.

During the conference, we focused on older adults as caregivers, volunteers, workers, and life-long learners. We used the same conceptual framework to present the papers in this special double issue of Ageing International. In the first issue, we set the stage more generally, by introducing the productive engagement perspective on population aging as well as participation trends in China. We also include analyses on the productive behaviors of caregiving and employment. In the second issue to follow, we focus on volunteering, community-based organizations and future directions.

We are grateful to many organizations and people, especially two senior social scientists in China. Professor Wu Cangping, Institute of Gerontology, Renmin University of China, provided insightful comments at the conference, and he serves as a role model of productive aging. He is truly the "Father of Gerontology in China." Professor Wang Sibin, Co-director of China Social Work Research Centre and Professor at the Department of Sociology at Peking University, also provided valuable insights into what productive aging really means for the older population in China context. He emphasized that the development of productive engagement policy and practice requires professional social work skills. 
Finally, we thank the editors of Ageing International, and the publisher Springer Press for guidance and production of this volume, and for their cordial cooperation with Peking University Press in publishing the conference volume in Chinese. We hope that this work advances knowledge and skills in research as well as program and policy development in different countries on a very important topic in regards to population aging - the productive involvement of older adults.

\section{References}

Longman, Philip. (2010). "Think again: Global aging.” Foreign Policy, November.

Morrow-Howell, N., Hinterlong, J., \& Sherraden, M. (2001). Productive aging: Concepts and challenges. Baltimore: Johns Hopkins University Press.

Nancy Morrow-Howell, MSW, PhD is the Ralph and Muriel Pumphrey Professor of Social Work at the George Warren Brown School of Social Work and the Director of the Harvey A. Friedman Center for Aging at Washington University in St. Louis. She studies the productive engagement of older adults and teaches gerontology and research courses.

Ada C. Mui, PhD, ACSW, LMSW is currently a Professor at the Columbia University School of Social Work in New York City. She is also a Faculty Associate at the Center for Social Development, Washington University in St. Louis. Internationally, she has been a Fellow at the Sau Po Center on Ageing at the University of Hong Kong; an Honorary Professor at Beijing Normal University, Beijing Youth Politics College, and the University of Hong Kong, China. In Taiwan, she is a Research Fellow at the Social Policy Research Center at the National Taiwan University. 